\title{
Nova Dimensão Para a Palavra "Estatuto"
}

HUGO LUIZ GURJÃO DE MELLO

Assistente Jurídico do DASP

\begin{abstract}
"Estatuto dos Servidores Públicos Civis Federais" - é o preceituário mínimo de normas, estáveis e cogentes, sôbre a natureza e a movimentação, inclusive provimento e vacância, dos cargos e empregos públicos e sôbre o complexo de deveres e responsabilidades de seus ocupantes, estabelecidas em lei, para serem observadas e cumpridas, com respeito e civismo, indistintamente por todos os servidores, mercê de compromisso unilateral assumido, automàticamente, no ato da investidura, como condição inerente a êle, em razão axiomática de ordem pública que não pode ser modificada pela vontade particular, ainda que ocorra contrato com característica bilateral.
\end{abstract}

Introduzir nôvo conceito para a palavra "estatuto" demanda imediatas considerações sôbre os vários significados a que responde o vocábulo, quer isoladamente, quer modificado por outras expressões.

Não chega a parecer-me necessário registrar o resultado completo da pesquisa a que procedi pessoalmente nesse sentido, consultando dicionários, enciclopédias e vários estatutos.

Realizei-a em direção à semântica, pouco preocupado com os espíritos epistemólogos e disposto a propor o nôvo enfoque, mesmo sem conotação.

Impende, porém, mencionar pelo menos parte da investigaÇão para conduzir o raciocínio que pretendo desenvolver.

Demais disso, tal omissão ensejaria críticas ligadas à semasiologia, por parte da oposição sistemática dos conservadores que condenam qualquer novidade, só por ser novidade. 
Assim, para prevenir a sagacidade dos dogmáticos deslumbrantes, começo por selecionar da compilação que o ilustre Professor Oswaldino Marques fêz especialmente para êste artigo, honrando-me com sua proficiente colaboração, o seguinte trecho:

\section{"ESTATUTO -}

Do baixo latim statutum, do latim, neutro de statutus, part. passado de statuere, manter de pé, pôr em pé, estacionar; de status, part. passado de stare, ficar em posição erecta.

Algo assentado ou formulado ou tido por fixo ou estabelecido, tal como:

a) o edito (decreto, proclamação) de um governante;

b) uma lei promulgada pela autoridade do ramo legislativo supremo de um govêrno, especialmente de um govêrno representativo;

c) um ato de uma corporação ou de seu fundador, visando a consubstanciar-se numa norma ou lei permanentes;

d) um instrumento internacional destinado a instituir um órgão e a regular seu escopo ou autoridade".

O estudo das origens e variantes da significação vocabular de "estatuto", feito pelo consagrado crítico (Estrutura das Ignorâncias Altamente Especializadas), dá-me cobertura lexicológica para eleger o seguinte conceito em relação à palavra "estatuto", isoladamente considerada:

Estatuto é o preceituário interno de normas estáveis e cogentes, emanadas da vontade da maioria de um grupo socialmente organizado e, portanto, imune à reação individual ou minoritária, dentro dêle.

Sob êsse aspecto, constitui mero continente formal, isto é, norma cogente, a variar de acôrdo com o conteúdo, geralmente indicado ou restringido pelas expressões que o modificam internamente, de conformidade com seus destinatários, uma sociedade, uma associação, uma corporação, ou uma fundação (estatuto de banco, de clube, do policial etc.).

Partindo daí, e eis a aplicação prática da novel conceituação, parece-me possível chegar a uma nova dimensão para a 
palavra, regendo-a com a expressão amplificadora "dos Servidores Públicos Civis Federais", conforme destacado no intróito:

ESTATUTO DOS SERVIDORES PÚBLICOS CIVIS FEDERAIS - é o preceituário mínimo de normas, estáveis e cogentes, sôbre a natureza e a movimentação, inclusive provimento e vacância, dos cargos e empregos públicos e sôbre o complexo de deveres e responsabilidades de seus ocupantes estabelecidas, em lei, para serem observadas e cumpridas, com respeito e civismo, indistintamente por todos os servidores, mercê de compromisso unilateral assumido, automàticamente, no ato da investidura, como condição inerente a êle, em razão axiomática de ordem pública que não pode ser modificada pela vontade particular ainda que ocorra contrato com característica bilateral.

Invadido, porém, o campo do Direito, particularmente o Administrativo, julgo oportuno buscar também cobertura doutrinária. O Vocabulário Jurídico, de De Plácido e Silva, foi o repositório mais completo de informações de quantos dicionários e enciclopédias consultei, e vale transcrever a parte relativa ao assunto, indo deliberadamente além do necessário, isto é, a conceituação da palavra isoladamente a acrescida da expressão "dos funcionários", não só para dar idéia de quantos usos permite a palavra, como também porque é um modo de oferecer à crítica todos os prós e contras que comportem os conceitos que ora defendo:

ESTATUTO. Derivado do latim statutum, de statuere (estabelecer, constituir, fundar), em sentido amplo, entendese a lei ou regulamento, em que se fixam os princípios institucionais ou orgânicos de uma coletividade ou corporação, pública ou particular (privada).

Em qualquer aspecto ou sentido, pois, o estatuto, geralmente dito no plural estatutos, exibe o complexo de normas ou regras observadas por uma instituição jurídica, a serem adotadas como lei orgânica, pelos quais, então, passa a ser regida.

Os estatutos podem trazer normas reguladoras de todos os atos e atividades da organização ou sociedade, como podem estabelecer regras reguladoras das relações dos elementos, que a compõem, com ela própria, impondo mesmo sanções para os atos dêles que possam ser contrários aos interêsses sociais, consistentes em sua exclusão ou suspensão de direitos, ou de outras penalidades, mesmo pecuniárias. 
Embora os estatutos, em relação às sociedades para que se estabelecem, assemelhem-se ao contrato por se mostrarem o instrumento em que se fixam tôdas as disposições que as irão reger, pròpriamente não se pode, em sentido exato, tomá-los por êle.

Em regra, o contrato, convenção das partes, impõe regras e obrigações entre elas, fazendo gerar, reciprocamente, entre os próprios sócios ou contratantes, obrigações exigiveis.

Em relação aos sócios, ou seja, em respeito às relações dêles, consideradas individualmente, os estatutos não apresentam caráter contratual. Apresentamse, depois de aprovados, como um pacto ou lei autônoma, que se diz a própria constituição fundamental da pessoa jurídica, por ela regulada. É um pacto coletivo.

Por sua essência, o contrato faz produzir direitos e obrigações entre os contratantes. Mas, pelos estatutos, tôdas as pessoas participantes da organização, por êles reguladas, assumem posição idêntica, havendo afinidades de interêsse, o que já os distancia do contrato, em regra promotor de relações jurídicas entre duas ou mais pessoas, ou sujeitos de direitos, onde, às mais das vêzes, os próprios objetos (interêsses) são opostos.

Estatuto. Mas, no sentido do Direito Civil, entende-se o conjunto de regras e princípios jurídicos que, em atenção ao estado da coisa e da pessoa, vem disciplinar as relações jurídicas que possam incidir sôbre as mesmas pessoas ou coisas. E, assim, diz-se estatuto pessoal, ou estatuto real.

No sentido do Direito Administrativo, refere-se ao complexo de princípios ou regras que regulam as atividades dos funcionários públicos, sejam civis ou militares, assegurando as vantagens e direitos sôbre o exercício dos respectivos cargos ou funções. É o estatuto dos funcionários.

ESTATUTO DOS FUNCIONÁRIOS: Denominação que se dá à lei especial, decretada com o objetivo de fixar as regras legais, reguladoras da situação do funcionário público, seja civil ou militar, nas quais se inserem as condições de provimento dos cargos ou funções públicas, os direitos e vantagens, os deveres e responsabilidades dos funcionários civis e militares. 
O estatuto dos funcionários civis e o estatuto dos militares de terra e de mar constituem-se em leis próprias, trazendo os requisitos elementares prescritos na lei constitucional, além de outras disposições que se constituem em deveres e obrigações funcionais e em vantagens inerentes ao cargo ou função desempenhada.

ESTATUTO FUNDAMENTAL. É o nome que se dá à Constituição Política de um país, que também é chamada de estatuto supremo, magna carta, lei magna, lei suprema.

ESTATUTO MISTO. É a denominação que se procura dar ao conjunto de normas reguladoras do ato, em face do princípio do locus regit actum.

E, consideram-no misto, porque, em boa razão, na execução do ato jurídico, em certo local, quando intervêm pessoas de nacionalidades diferentes, cada uma jungida a seu estatuto pessoal, no tocante à capacidade para a constituição do ato, é êste estatuto que a regula; mas, em relação à forma do ato jurídico ou à sua composição formal, é a lei local que o rege (locus regit actum).

Há, assim, a aplicação de leis relativas à pessoa, o que caracteriza o estatuto pessoal, extraterritorial, e de leis locais, decorrentes do estatuto real, referente à coisa ou ao ato que é territorial. $E$, por êste motivo, denominam-no de estatuto misto.

ESTATUTO PESSOAL. É a denominação usada no Direito Internacional Privado para indicar o conjunto de regras jurídicas que devem regular as questões de estado e de capacidade de uma pessoa, por serem elas encaradas como um atributo da própria pessoa.

Nesta condição, o estatuto pessoal quer traduzir o complexo de leis pessoais, a que está sujeita a pessoa, em virtude do que elas a acompanham, onde quer que vá.

Assim, o estatuto pessoal, indicando as leis pessoais que devem ser aplicadas às pessoas nas questões relativas a seu estado e capacidade, mostra também a qualidade extraterritorial das mesmas leis, pois que, aderindo às mesmas, assim como a lepra à pele (sicut lepra cuti), as acompanha por tôda a parte. 
ESTATUTO REAL. Expressão tradicionalmente usada, em oposição ao estatuto pessoal, para indicar o conjunto de leis que se referem ao regime da propriedade, à disposição e transmissão de bens, com abstração das pessoas, cujas leis se mostram territoriais, não importando as leis pessoais de quem quer que intervenha nos atos jurídicos, de que são os mesmos bens objeto.

Mas, a propriedade que se subordina ao estatuto real é a imobiliária. Para esta o princípio é o da lex rei sitae.

Quanto aos bens móveis, desde que trazidos pelo proprietário, adaptam-se à regra do mobilia sequuntur personam.

Entanto, segundo o estatuto real, devem os bens imóveis e móveis, para aplicação da lei, ser considerados ut singuli ou como universalidade.

Ut singuli, ou seja, considerados individualmente, estão subordinados à lei territorial.

Mas, como universalidade, que se constitui por todos os bens que possam pertencer a uma pessoa, que venha a falecer, já o estatuto real se excepciona para fazer valer a regra do direito pessoal do de cujus.

Como se vê, o conceito tradicional abrange sòmente o funcionário porque a lei tem cuidado apenas do ocupante de cargo público. Isto não é de estranhar, visto como, originàriamente, só havia mesmo a serviço do Estado, em caráter permanente, aquela espécie de servidor.

Além disso, quando se criou a figura do extranumerário, deu-se-lhe legislação própria, também de natureza estatutária, portanto, perfeitamente compatível com o Estatuto que pôde serthe aplicável no que coubesse (pràticamente tudo) e assim 0 fato não apresentava maior transtôrno.

Interessante, a propósito, notar que surgira o extranumerário da necessidade de contar a União com outra categoria de servidor que, embora desempenhasse também funções de caráter permanente, e portanto necessàriamente devesse ficar sujeito aos mesmos deveres e responsabilidades, se apresentasse com características menos pessoais, mais funcionais, menos duradouras, mais temporárias, menos formais, mais maleáveis. 
Entretanto, o idiossincrásico paternalismo do administrador de então e a desconfiança que êle inspirava ao legislador da época levaram os desorientados responsáveis pela política de pessoal, na ocasião, a promoverem a vedação de admissões de extranumerário, desencadeando, paradoxalmente, a proliferação de ingresso no serviço público, através de formas menos recomendáveis, por pessoal a quem não havia como aplicar as normas estatutárias.

Não obstante, a milagrosa transformação em funcionários da maioria dêsses servidores, o problema nunca foi superado e ainda subsiste em larga escala, porque foi aumentado o quadro do funcionalismo com servidores aos quais não é aplicável o Estatuto, como acontece em relação aos empregados públicos que dispõem de regime juridico próprio - a legislação trabaIhista. Esta, evidentemente, destinada a regular as relações entre empregados e empregadores na área privada não se comove com nenhuma das peculiaridades dêsse Patrão diferente que é o Estado.

Aliás, até pelo contrário, dêle mais exige como Empregador-Padrão, pois é quem dita as normas para os outros patrões, e, como resultado, figura êle como mera parte nas questões trabalhistas, conquanto seja digno de prerrogativas especiais de ordem pública e, o que é pior, não são consideradas nas próprias relações internas com seus empregados, no que concerne a deveres e responsabilidades.

Eis a grande vantagem do conceito que recomendo: distinguir nitidamente das normas dinâmicas de direitos e vantagens, que estão sempre a demandar controvérsias por parte dos servidores, qualquer que seja o regime jurídico, aquelas que, em razão de sua natureza estática e cogente, não admitem contestação, porque devem ser erga omnes, observadas e cumpridas com respeito e civismo, tanto por funcionários, como por empregados.

Com efeito, são uns e outros servidores públicos e, em decorrência, automática e obrigatòriamente, devem estar sujeitos ao arbítrio maior do interêsse coletivo, naquilo que puder afetar a estrutura basilar da política de pessoal do Govêrno, ipso facto, com prejuízo para a atividade-meio do Estado, em têrmos de segurança nacional.

Poder-se-ia, dêsse modo, estender a todos os servidores campo de incidência do Estatuto, com o simples recurso de escoimá-lo das questionadas normas sôbre direitos e vantagens, as quais, tal como as relativas à retribuição e classificação de 
cargos e empregos, iriam constituir códigos paralelos e independentes. Isso, além de tècnicamente mais perfeito, daria ao Estatuto, conseqüentemente, maior durabilidade, estaticidade e atualidade, reduzindo, ainda, consideràvelmente, o número de demandas dos servidores, porque eliminaria, radicalmente, as reivindicações ligadas às disposições preceptivas e cogentes.

Urge, assim, pôr mãos à obra e começar a separar o joio do trigo, para elaborar um Estatuto com a nova dimensão proposta e, sem dúvida, preparar, paralela e concomitantemente, os outros instrumentos legais aludidos, sôbre direitos, vantagens, retribuição e classificação de cargos e empregos ... 